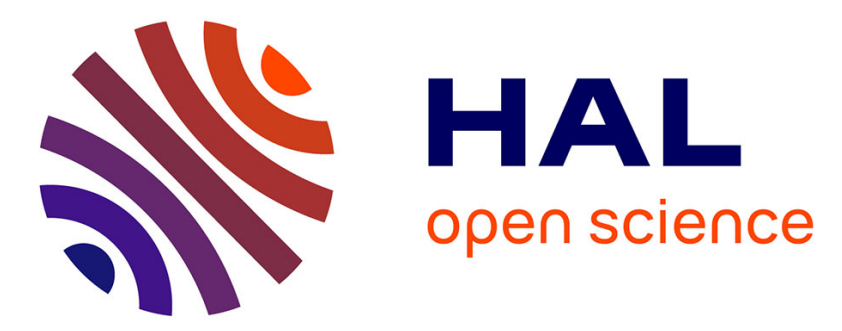

\title{
Plasma growth processes inside gaps of the castellated limiter of the Tore Supra tokamak
}

\author{
R. Ruffe, C. Martin, C. Pardanaud, G. Giacometti, P. Languille, P. Roubin, \\ B. Pégourié
}

\section{- To cite this version:}

R. Ruffe, C. Martin, C. Pardanaud, G. Giacometti, P. Languille, et al.. Plasma growth processes inside gaps of the castellated limiter of the Tore Supra tokamak. European Physical Journal: Applied Physics, 2011, 56 (2), pp.24027. 10.1051/epjap/2011110171 . hal-00746210

\author{
HAL Id: hal-00746210 \\ https://hal.science/hal-00746210
}

Submitted on 28 Oct 2012

HAL is a multi-disciplinary open access archive for the deposit and dissemination of scientific research documents, whether they are published or not. The documents may come from teaching and research institutions in France or abroad, or from public or private research centers.
L'archive ouverte pluridisciplinaire HAL, est destinée au dépôt et à la diffusion de documents scientifiques de niveau recherche, publiés ou non, émanant des établissements d'enseignement et de recherche français ou étrangers, des laboratoires publics ou privés. 
EPJ manuscript No.

(will be inserted by the editor)

\title{
Plasma growth processes inside gaps of the castellated limiter of the Tore Supra tokamak
}

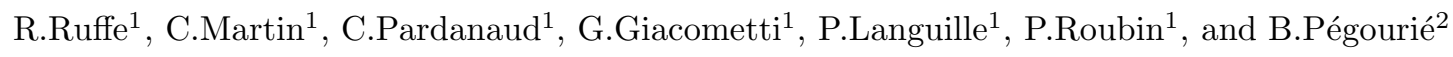 \\ 1 Laboratoire PIIM, UMR 6633, Centre St Jérôme, 13397 Marseille cedex 20 \\ 2 Association Euratom-CEA sur la Fusion Contrôlée, Cadarache F-13108 St Paul Lez Durance cedex
}

Received: date / Revised version: date

\begin{abstract}
We performed electron microscopy analysis of carbon tiles dismantled from the toroidal limiter of the Tore Supra tokamak. The tile top surfaces are either eroded, or covered with deposits, depending on ion flux. On the contrary, the tile gap surfaces are covered with deposits whatever the region of the limiter. We analyzed both the topography and the microstructure of gap deposits. Deposits are tip-shaped and deposition is significant only down to $\sim 1 \mathrm{~mm}$, due to the limited penetration of ions. The direction of tips results from the combination of the ion speed along the magnetic lines and the drift associated to the local electric fields. The microstructure of deposits reveals the presence of graphitic species, such as onion-like nanoparticles, and our results therefore show that deposition results from local plasma chemistry similar to what is observed for cold plasmas.
\end{abstract}

\section{Introduction}

In tokamaks, a quasi-toroidal magnetic field confines a hot plasma to study D/T fusion reactions. During plasma discharges, ions strongly interact with the plasma-facing components (PFCs) which are often designed in carbon to resist to high power loads. The main PFC of the Tore Supra (TS) tokamak (Cadarache, France), is the Toroidal Pumped Limiter (TPL), a castellated structure designed with tiles in $\mathrm{C} / \mathrm{C}$ composite (sepcarb®N11). Close to the TPL surface, typical temperatures are $\sim 20-70 \mathrm{eV}$ for the electrons, $\sim 60-200 \mathrm{eV}$ for the ions, falling rapidly by more than an order of magnitude in gaps between tiles. The castellation and a curved design of the tile edges allow the TPL to resist to power loads as high as $10 \mathrm{MW} \cdot \mathrm{m}^{-2}$, which are also the values expected for ITER. Due to ion irradiation, carbon is eroded and carbon deposits are formed, leading to unwanted $\mathrm{D} / \mathrm{T}$ retention.

To study retention, tiles were dismantled from the TPL for post-mortem analyses, on which Scanning and Transmission Electron Microscopy (SEM and TEM) were performed. The top surface (the main surface in contact with the plasma), and the four lateral surfaces in the gaps were analyzed. Since previous results $[1,2]$ showed that gaps play a key role in the retention, we focus here on gap surfaces. The aim is to get from the topography and microstructure of gap deposits information on the growth processes and the local plasma inside gaps.

\section{Methods}

Fig. 1 shows a picture of the dismantled part of the TS TPL displaying different zones TPL: due to the configuration of the TS magnetic field, the interaction between the plasma and the TPL is non-homogeneous and the TPL surface exhibits a periodic pattern with erosion dominated zones and deposition dominated zones. The deposition zones are split into thick deposit zones and thin deposit zones.

TPL tiles (C/C composite) are $\sim 2 \times 2 \mathrm{~cm}$ large and $0.6 \mathrm{~cm}$ thick. To lower power loads, edges are curved in the poloidal direction (curvature radius is $2 \mathrm{~mm}$ ). We analyzed several tiles, extracted from different TPL zones. The tile orientation is referred to the magnetic field configuration by the High and Low Field Side in the poloidal direction (HFS and LFS) and the Up-Stream and DownStream side (US, DS) in the toroidal direction (Fig.1). Electron microscopy was performed at CP2M analysis center, Marseille. Deposit topography was investigated by SEM [3], and deposit microstructure was investigated by TEM on samples extracted from the deposits by two means: (i) scraping deposits off the surface with a thin blade, the obtained powder then placed in $\mathrm{CCl}_{4}$ and dispersed with ultrasound, and (ii) cutting a thin foil by FIB technique [4], the deposit surface being coated with a thin platinum layer before cutting to avoid damages of the microstructure under ion beam irradiation. 


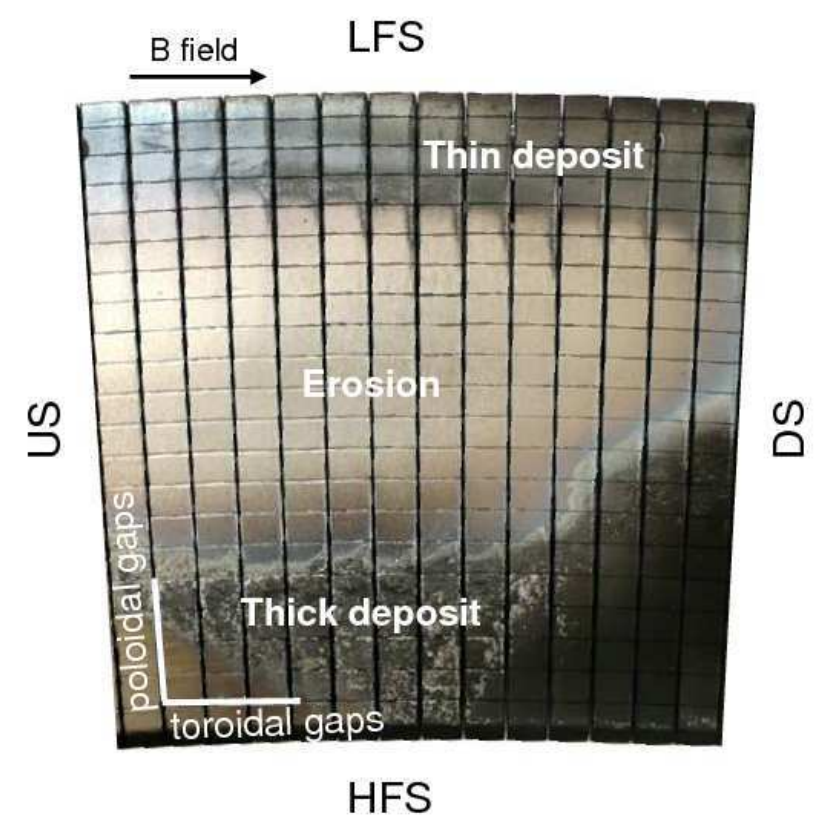

Figure 1. Part of the Tore Supra toroidal pump limiter. High Field and Low Field Sides (HFS and LFS), as well as UpStream and Down-Stream sides (US and DS) are indicated. The erosion zone (shiny), thin deposit zone (blueish/black), and thick deposit zone (grey/looking coarse) are indicated.

\section{Results}

Fig 2 shows a front view of a typical poloidal gap side (a) and toroidal gap side (b). In the case of poloidal gaps, close to the tile top, deposits are tip-shaped, with a dendritic structure observed at the tip base. Tips point mainly towards the LFS side, slightly towards the top surface $(\sim$ $10^{\circ}$ between the tip and the poloidal directions). In the case of toroidal gaps: tips are oriented vertically towards the top. For both cases, no deposition is observed below $\sim 1 \mathrm{~mm}$. There is also a clear asymmetry in the toroidal deposit thickness, LFS deposits being always significantly thicker than HFS deposits. Remarkably, the main gap deposit features such as topography and tip orientation are similar wherever the tile on the TPL.

Fig. 3 is a TEM image of powder scraped off the DS poloidal gap of a thick deposit tile: it shows the presence of these onion-like graphitic nanoparticles, similar to those previously observed in TS. This is a clear confirmation of the existence of gas phase growth processes at the plasma edge of tokamaks [5]. Deposits are heterogeneous: TEM analysis also shows graphitic layers alternating with amorphous carbon layers, indicating that plasma conditions and therefore growth processes can significantly vary.

\section{Discussion}

Although the different zones of the TPL surface look very different (smooth and eroded surface or rough surface cov-

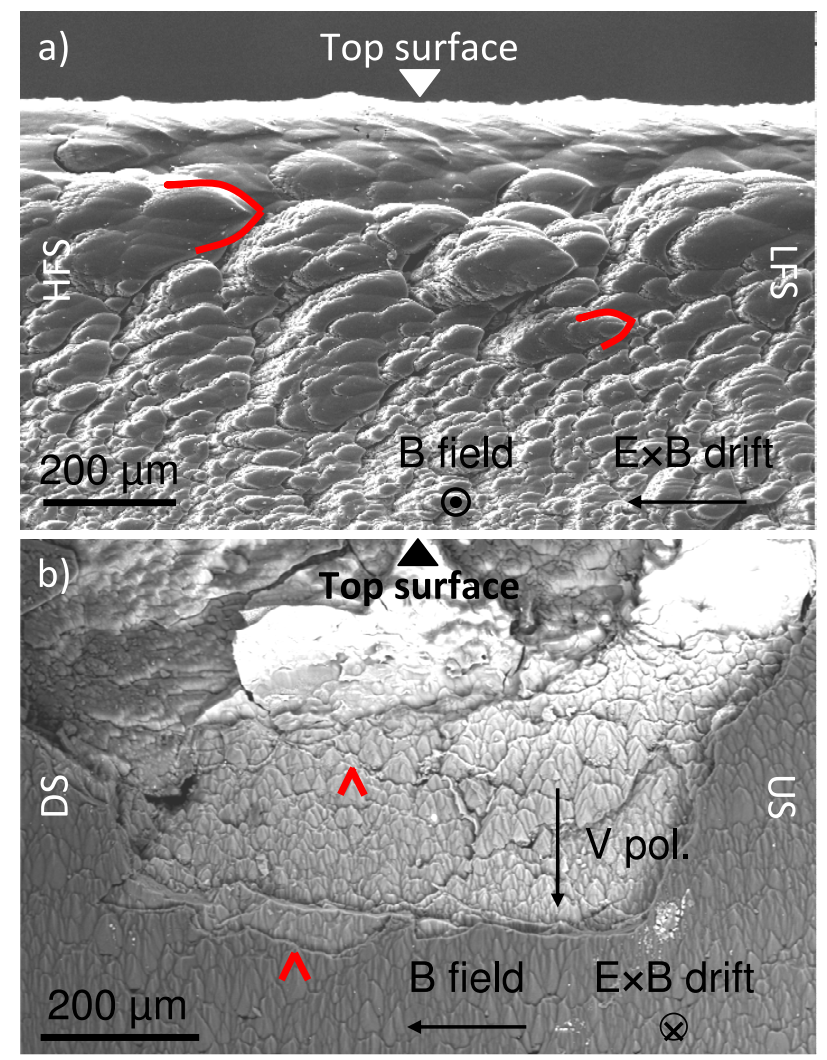

Figure 2. SEM images of (a) the US poloidal gap of an eroded tile, and (b) the LFS toroidal gap of a thick deposit tile. Some tips are underlined in red for clarity. Direction of the B field, the $E \times B$ and polarization drifts, are also indicated

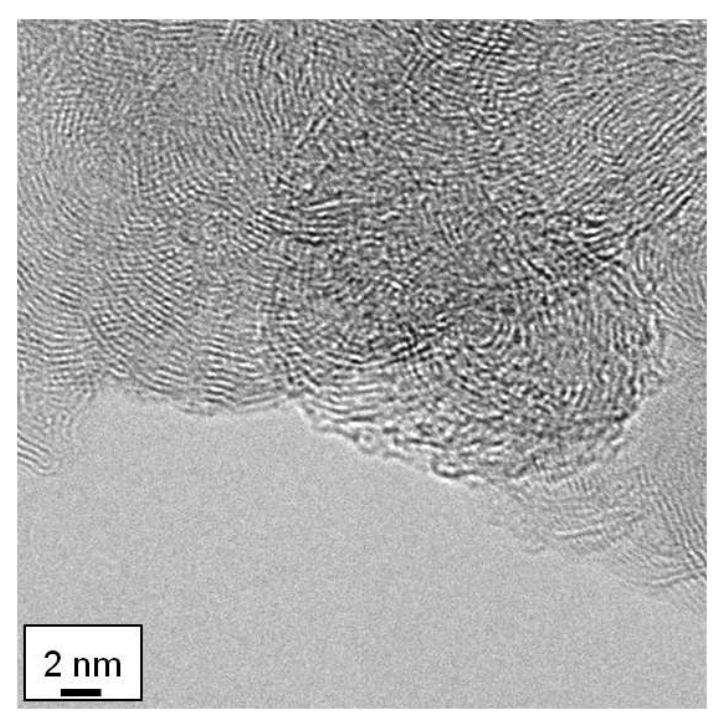

Figure 3. TEM image of powder scraped off the DS poloidal gap of a thick deposit tile. 
ered with deposits), all the gaps are dominated by deposition all over the TPL surface, in agreement with previous results in TEXTOR [6]. This indicates that there are, inside gaps, similar processes for the deposit formation, only slightly dependent on the ion irradiation conditions. Ions are convected along the magnetic field. However, field line penetration inside gaps $(\lesssim 0.2 \mathrm{~mm})$ is not enough to explain the observed deposition depth down to $1 \mathrm{~mm}$ and local electric drift together with the finite size of Larmor orbit also contribute [7]. The different topography between the poloidal and toroidal gap deposits (different tip direction) indicates the prominent role played by the relative orientation of the B field with respect to that of the gap. The tip direction is related to the component of the ion flow velocity parallel to the surface. The latter results from the balance between the parallel velocity (quasi-toroidal, along the magnetic field), the local $E \times B$ drift (quasipoloidal, towards HFS) and the polarization drift (vertical, towards the surface). As a consequence of this balance, we observe that for poloidal gaps, tips are pointing mainly towards LFS, while for a major part of the toroidal gaps , tips are quasi-vertical. The poloidal $E \times B$ drift yields an asymmetry between LFS/HFS surfaces of the toroidal gaps [7] which can be correlated to the different deposit thicknesses.

The TEM analysis of powders scraped off the toroidal gap deposits shows the presence of onion-like graphitic nanoparticles. Due to the high ion and electron temperatures at the TPL surface (few tens of eV), they cannot be created in colder remote areas and be transported by the ion flow up to the gaps [8]. This reveals that homogeneous growth ${ }^{1}$ takes place in the in-gap residual plasma, similarly to what is observed in cold plasma processes.

\section{Conclusion}

Understanding the formation of the deposits due to the erosion/deposition processes at the edge of tokamaks is important due to the associated $\mathrm{D} / \mathrm{T}$ retention. To this aim, gap deposit topography was studied by SEM (shape, direction of the tips, deposition depth and thickness) for tiles originating from different places of the TPL. Information was obtained on the direction of impinging ion flow and electric field in the gaps. TEM analysis of the deposit microstructure, by revealing the presence of onionlike graphitic nanoparticles demonstrated the existence of homogeneous growth inside the in-gap residual plasma.

\section{References}

1. B. Pégourié et al., J. Nucl. Mater. 390-391, (2009) 550-555

2. E. Tsitrone et al., Nucl. Fusion 49, (2009) 075011

\footnotetext{
1 Ion energies are about a few hundreds of eV, by far too low for these nanoparticles to be created through heterogeneous growth induced by ion bombardment, which requires ion energies of the $\mathrm{MeV}$ order of magnitude.
}

3. C. Martin et al., J. Nucl. Mater. (2010), doi:10.1016/j.jnucmat2010.11.006

4. D.M Allen et al., CIRP Annals - Manufacturing Technology 58, (2009) 647-662

5. M. Richou et al, Carbon 45, (2007) 2723-2731

6. A. Litnovsky et al., J. Nucl. Mater, doi:10.1016/j.jnucmat.2010.12.018

7. R. Dejarnac, J.P Gunn, J. Nucl. Mater. 363-365, (2007) 560-564

8. P. Roubin et al., J. Nucl. Mater. 390-391, (2009) 49-52 